\title{
OPTIMALISASI KINERJA ANGKUTAN UMUM DITINJAU DARI ASPEK KEPENGUSAHAAN STUDI KASUS TRAYEK 32 JURUSAN TERMINAL CIKARANG (5GC)- WARUNG BONGKOK-SUKADANAU- JATIWARINGIN
}

\author{
Sugita, SE, MM \\ Dosen STTD \\ Jl. Raya Setu No. 89, Cibuntu, \\ Cibitung, Bekasi 17520 \\ Telp./Fax : (021) 8254640
}

\author{
Asrizal, ATD, MM \\ Dosen STTD \\ Jl. Raya Setu No. 89, Cibuntu, \\ Cibitung, Bekasi 17520 \\ Telp./Fax : (021) 8254640
}

\author{
Ika setyorini, Spsi, MSi \\ Dosen STTD \\ J1. Raya Setu No. 89, Cibuntu, \\ Cibitung, Bekasi 17520 \\ Telp./Fax : (021) 8254640
}

\author{
Ubaini Rasyid, MM \\ Dosen STTD \\ Jl. Raya Setu No. 89, Cibuntu, \\ Cibitung, Bekasi 17520 \\ Telp./Fax : (021) 8254640
}

\author{
Nugraini Wulandari, Ama Pkb \\ Instruktur STTD \\ Jl. Raya Setu No. 89, Cibuntu, \\ Cibitung, Bekasi 17520 \\ Telp./Fax : (021) 8254640
}

\begin{abstract}
ABSTRAKSI
Semakin meningkatnya kebutuhan masyarakat akan transportasi membuat Angkutan Umum harus meningkatkan kinerjanya baik secara kualitas maupun kuantitas. Oleh karena itu diperlukan suatu tindakan untuk mengetahui kinerja dari pada suatu angkutan tersebut, yaitu berupa survey yang diantaranya adalah survey on bus, survey statis dan survey wawancara penumpang

Pada penelitian ini akan dilakukan kajian terhadap Kinerja angkutan K-32 Kabupaten Bekasi yang nantinya akan di evaluasi kinerjanya serta bagaimana arah pengembangannya untuk meningkatkan mutu pelayanan angkutan umum tersebut.

Asumsi pengoperasian angkutan berdasarkan penghitungan jumlah armada yang sudah sesuai dengan peraturan Dirjen darat yaitu sebanyak 56 unit angkutan tiap hari. Dalam pengoperasian angkutan disesuaikan dengan jumlah penumpang. Penjadwalan ini dipertimbangkan dengan asumsi penjadwalan berdasarkan clock face
\end{abstract}

kelayakan usaha trayek K-32 didapatkan layak untuk dilanjutkan, dengan asumsi jumlah armada 56 unit, sedangkan nilai balik investasi selama 4 tahun 2 bulan

\section{ABSTRACT}

The increasing of the needs of the community to transportation will make the Public Service should improve its performance both in quality and quantity. Therefore we need an action to determine the performance of one of the freight, in the form of surveys which include a survey on the bus, static survey and interview survey of passengers

This research will be conducted studies on transport performance K-32 district of Bekasi which will be the evaluation of its performance and how its development direction to improve the quality of public transport services.

Assumptions transport operation by counting the number of fleets that are in accordance with the regulations of Land Transport General Director as many as 56 units per day. In the 
operation of transport depends on the number of passengers. Scheduling is considered assuming scheduling based on the clock face

The trajectory properness of K-32 has been found worthy to proceed, assuming a fleet of 56 units, while the value of return on investment for 4 years and 2 months.

\section{PENDAHULUAN}

\section{A. LATAR BELAKANG}

Transportasi merupakan salah satu elemen penting dari suatu daerah perkotaan. Fasilitas transportasi memiliki potensi untuk mengendalikan arah dan besarnya perkembangan kota baik dalam sektor perekonomian maupun sektor lainnya. Transportasi merupakan bagian penting dari suatu kota, dimana kemajuan suatu kota dapat diukur dari seberapa jauh perkembangan dan kemajuan transportasi yang ada di kota tersebut.

Pertumbuhan pembangunan ekonomi perkotaan tidak lepas dari pengaruh investor sebagai sektor swasta. Besarnya pengaruh peran sektor swasta dalam perkembangan kota dapat menyebabkan wilayah terbangun berkembang dengan pesat secara horisontal dan tak terkendali. Pembangunan yang ada lebih mementingkan kebutuhan manusia dimana perencanaan yang ada mengarah kepada kehidupan praktis dan kenyamanan manusia akibat dari dampak hidup modern, sehingga tidak tertatanya kota dengan baik dan perencanaan kota yang terkadang mengabaikan pertimbangan aspek lingkungan yang mengakibatkan banyaknya lahan-lahan yang beralih fungsi, terutama lahan resapan yang beralih fungsi menjadi lahan terbangun dan lahan komersial yang menyebabkan tidak adanya keseimbangan lahan terbangun dan lahan tidak terbangun di suatu kota.

Semakin meningkatnya kebutuhan masyarakat akan transportasi membuat Angkutan Umum harus meningkatkan kinerjanya baik secara kualitas maupun kuantitas. Oleh karena itu diperlukan suatu tindakan untuk mengetahui kinerja dari pada suatu angkutan tersebut, yaitu berupa survey yang diantaranya adalah survey on bus, survey statis dan survey wawancara penumpang

Pada penelitian ini akan dilakukan kajian terhadap Kinerja angkutan K-32 Kabupaten Bekasi yang nantinya akan di evaluasi kinerjanya serta bagaimana arah pengembangannya untuk meningkatkan mutu pelayanan angkutan umum tersebut. 


\section{B. RUMUSAN MASALAH}

Salah satu sarana transportasi yang memegang peranan penting dalam mendukung aktivitas manusia khususnya masyarakat Kabupaten Bekasi adalah angkutan umum.

a. Masyarakat pada daerah warung bongkok, sukadanau dan jatiwangi mayoritas bekerja sebagai karyawan pabrik di kawasan industri untuk itu penting untuk dilakukan evaluasi mengenai jaringan trayek pada daerah tersebut dalam hal ini $\mathrm{K}$ 32, agar dapat mengakomodir perjalanan pulang pergi Karyawan pabrik.

b. Sistem pemberangkatan yang tidak teratur serta kondisi kendaraan yang buruk berakibat pada rendahnya minat masyarakat untuk menggunakan angkutan umum.

c. Sistem setoran yang di terapkan mengakibatkan pendapatan sopir angkutan yang tidak menentu dan kadang merugi di akibatkan karena sewa kendaraan dan bahan bakar yang tinggi dan pengemudi yang kadang merugi.

d. Jumlah armada yang menurut informasi masyarakat semakin menurun jumlahnya.

\section{A. TRAYEK K-32 DALAM SISTEM JARINGAN}

K-32 merupakan suatu rute pelayanan angkutan penumpang umum yang melayaniperjalanandariJurusan Terminal Cikarang (SGC) - Warung Bongkok Sukadanau- Jatiwangi yang berada pada Kabupaten Bekasi.

Pergerakan perjalanan masyarakat yang berada di sekitarSGCdan Kelurahan Jatiwangi dipenuhi dengan adanya pelayanan angkutan penumpang umum.

\section{Kelurahan Jatiwangi}

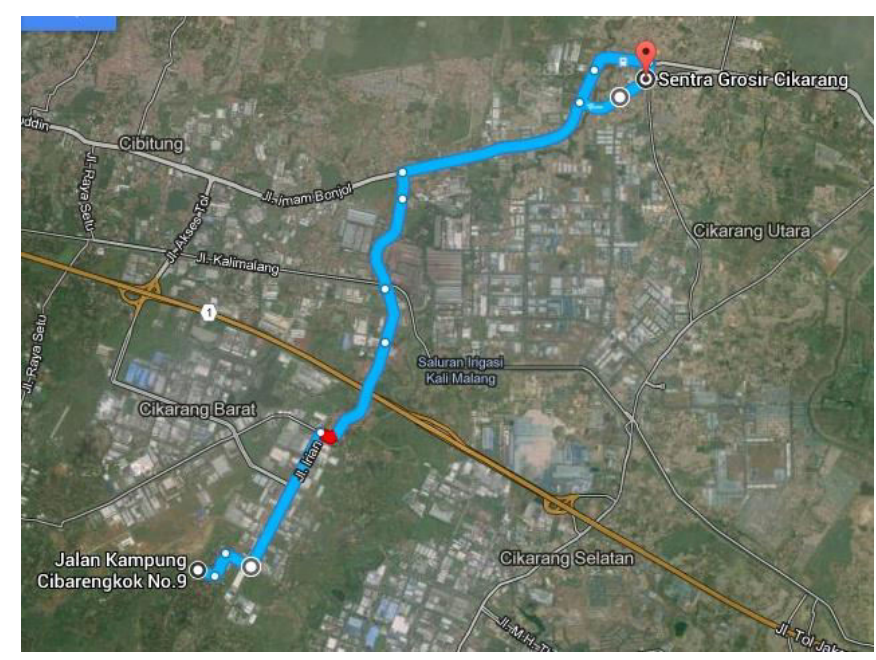


Bagan Alir Penelitian

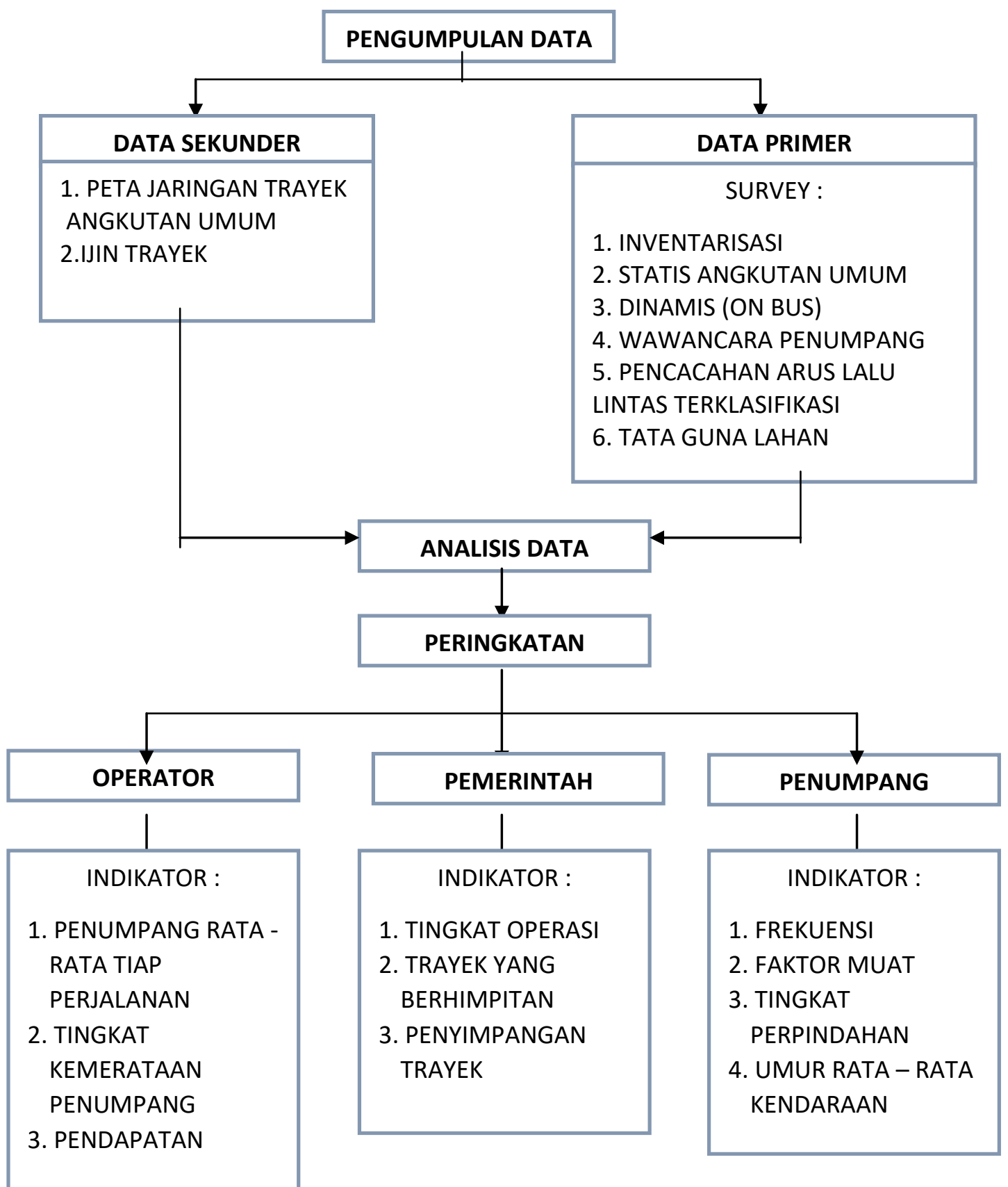

\section{PENYAJIAN DATA}

\section{A. Survai Inventarisasi Angkutan Umum}

1. Penyajian Data

Dari hasil pengamatan survay inventarisasi angkutan umum kami peroleh dari data sekunder serta data primer. Adapun data sekunder yang kami dapat dari Dinas Perhubungan Bekasi 
Adapun hasil dari data primer yang kami peroleh dari survai langsung ke lapangan, yaitu sebagai berikut :

1. Nomor trayek : K-32

2. Rute

: SGC- Jatiwangi

3. Warna

: Merah

4. Jumlah armada yang beroperasi $\quad: 80$

5. Jumlah armada yang diizinkan : $: 74$

6. Jumlah rit perhari : 3

7. Panjang trayek

$: 12,5 \mathrm{~km}$

8. Tarif

: Rp 6000,00

9. Umur kendaraan

: Rata-rata 12 tahun

10. Jenis angkutan umum

: Carry

11. Kepemilikan

: Perorangan

12. Pejabat pemberi izin

: Walikota Bekasi dan Pemkab Bekasi serta diketahui oleh Dinas

Perhubungan kota Bekasi

13. Sistem Pemberangkatan

: Tidak terjadwal

14. Asal dan Tujuan trayek

: Cikarang - Jatiwangi

15. Kantong Penumpang

: Cikarang (SGC)

Jarakosta

Warung Bongkok

2. Analisis dan Pembahasan

Dalam survai inventaris ini dapaat diketahui bahwa :

$\checkmark$ Jenis kendaraan dari trayek K32 ini adalah carry yang berwarna merah

$\checkmark$ Kapasitasnya 12 penumpang

$\checkmark$ Umur rata-rata dari kendaraan itu yaitu rat-rata dibuat pada tahun 1999, yaitu kurang lebih berumur 12 tahun. Keadaan fisik dari angkutan ini cukup baik, karena pada angkuatan ini diperoleh informasi bahwa sering dilakukan peremajaan seperti pengecetan, perbaikan mesin, dll sehingga kondisi fisiknya masih terlihat cukup baik.

$\checkmark$ Kepemilikan dari angkutan ini adalah perorangan, dimana para sopir menyetorkan hasil tarikannya pada pemilik angkutan. Penyetoran uangnya menurut para sopir seharinya kurang lebih Rp 80.000,- atau maksimal Rp 100.000,- tergantung dari ramai atau tidaknya angkutan tersebut. 
Kantong-kantong penumpangnya paling banyak di Warung bongkok, karena di warung bongkok ini merupakan persimpangan yang ramai.

$\checkmark$ Model pemberangkatan dri angkutan ini itu tidak terjadwal, tergantung dari jumlah penumpangnya, namun bukan hanya jumlh penumpang saja yang mempengaruhi keberangkatan dari angkutan ini yaitu kebutuhan dari sopir angkutan tersebut. Jika sopir tersebut ingin melanjutkan perjalanan maka lanjut, jika sopir masih ingin menunggu penumpang maka angkutan itu akan menunggu penumpang.

$\checkmark$ Waktu yang diperlukan untuk melakukan perjalanan dari SGC- Warung Bongkok - Jatiwangi yaitu 40 menit.

$\checkmark$ Jam sibuk dari angkutan ini yaitu pagi hari dan sore hari saat orang mengawali aktifitas dan mengakhiri aktivitas.

Adapun dari pelaksanaan survai tersebut diketahui terdapat beberapa perbedaan dengan data sekunder dengan data primer yang kami lakukan saat survai, yang diantaranya :

\section{$\checkmark \quad$ Penyimpangan Trayek}

Menurut izin trayek dari dinas perhubungan izin rute untuk trayek K32 ini adalah sampai di Sukadanau, namun pada kenyataannya di lapangan, angkutan umum K32 ini berakhirnya di Jatiwangi.

Memang tujuan terakhir trayek ini adalah K32, namun sangat banyak juga angkutan umum K32 ini tidak sampai di Jatiwangi, mereka hanya sampai di Sukadanau dan kemudian berputar balik tergantung dari penumpangnya. Jika penumpangnya ada yang akan menuju Jatiwangi maka angkutan ini akan berhenti di Jatiwangi.

Warung bongkok adalah tempat kebanyakan para sopir angkutan melakukan putar balik, karena pada titik inilah paling banyaknya naik turun peumpang.

\section{$\checkmark \quad$ Jumlah Armada yang beroperasi}

Jumlah armada yang mendapat izin sesuai data sekunder yaitu 74. Menurut wawancara yang dilakukan kepada sopir-sopir setempat diperoleh hasil bahwa kendaraan yang beroperasi yaitu 80 .

Pada saat kita melaksanakan survai, kendaraan yang beroperasi adalah 70 . Dari data tersebut dapat kita ketahui bahwa terjadi penyimpangan jumlah armada. Jumlah armada yang beroperasi tidak sesuai dengan jumlah yang 
mendapat izin dari dinas perhubungan . Hal tersebut menunjukkan bahwa banyak kendaraan yang beroperasi tanpa izin.

\section{$\checkmark \quad$ Tarif}

Berdasarkan data sekunder tarif yang dikenakan adalah $\mathrm{Rp} 6000,00$, dalam kenyataannya tarf yang di kenakan yaitu benar memang $\mathrm{Rp}$ 6000,00 , namun terdapat perbedaan tarif yang di dasarkan atas status , yang diantaranya yaitu :

Untuk umum Rp 6.000,00

Untuk Pelajar Rp 4.000,00

\section{ANALISIS BIAYA OPERASIONAL KENDARAAN DAN TARIF}

\section{ANALISIS BOK}

BOK ini bertujuan untuk menghitung biaya yang dikeluarkan oleh operator dalam memproduksi jasa angkutan dalam seat per km. Dalam perhitungan BOK diperlukan data-data mengenai harga komponen dari kendaraan yang berlaku saat ini, data-data ini didapat penulis dari hasil analisis terhadap biaya komponen kendaraan yang berlaku. Berikut beberapa asumsi yang digunakan dalam menghitung BOK:

Untuk hasil rekapitulasi Perhitungan BOK dapat dilihat pada Tabel:

Tabel V.20 Rekapitulasi Biaya

\begin{tabular}{|c|c|c|c|}
\hline \multicolumn{4}{|c|}{ REKAPITULASI BIAYA OPERASI KENDARAAN } \\
\hline Biaya Langsung & & & \\
\hline - Penyusutan & $: \quad \mathrm{Rp}$ & 378 & ,- \\
\hline - Bunga modal & $: \mathrm{Rp}$ & 140 & , - \\
\hline - Gaji dan tunjangan awak Bus & $: \mathrm{Rp}$ & - & $\overline{,-}$ \\
\hline - B B M & $: \mathrm{Rp}$ & 1,238 & $\overline{,-}$ \\
\hline - Ban & $: \mathrm{Rp}$ & 9.52 & ,- \\
\hline - Servis kecil & $: \mathrm{Rp}$ & 8.60 & ,- \\
\hline - Servis besar & $: \mathrm{Rp}$ & 14.99 & $\overline{,-}$ \\
\hline - General Overhoul & $: \mathrm{Rp}$ & - & ,- \\
\hline - Penambahan oli mesin & $: \mathrm{Rp}$ & 22.94 & $\overline{,-}$ \\
\hline - Cuci Bus & : $\mathrm{Rp}$ & - &,- \\
\hline - Retribusi Terminal & $: \mathrm{Rp}$ & 59.52 & ,- \\
\hline - STNK & : $\mathrm{Rp}$ & 47.24 & $\overline{,-}$ \\
\hline - Keur & : $\mathrm{Rp}$ & 4.72 & ,- \\
\hline
\end{tabular}




\begin{tabular}{|c|c|c|c|}
\hline - Asuransi & $: \mathrm{Rp}$ & 0.00 & ,- \\
\hline Jumlah & $: \mathrm{Rp}$ & 1,924 & , - \\
\hline Biaya Tidak Langsung & & & \\
\hline - Biaya perizinan & $: \mathrm{Rp}$ & 11.81 &,- \\
\hline - Biaya seragam & $: \mathrm{Rp}$ & 0.00 &,- \\
\hline - Biaya Karcis dan ATK & : $\mathrm{Rp}$ & 0.00 &,- \\
\hline Jumlah & $: \mathrm{Rp}$ & 11.81 & ,- \\
\hline BOK PER KM & : $\mathrm{Rp}$ & 1,936 & \\
\hline BOK PER TAHUN & $: \mathrm{Rp}$ & $117,070,295$ & ,- \\
\hline
\end{tabular}

Sumber: Hasil Analisis Penulis

Jadi BOK trayek SGC - Jatiwangi per seat km adalah sebesar Rp. 1,936/ km.

\section{Analisis Tarif}

a. Perhitungan Tarif

Tarif untuk angkutan yang dibebankan pada seluruh penumpang angkutan, untuk itu Biaya Operasi Kendaraan per-km sebesar Rp. 1,936 harus di koversikan menjadi Biaya operasi Kendaraan per-tahun untuk bisa di bagi jumlah penumpang per-tahun.

Tarif $=[($ BOK $+($ BOK $\times 10 \%) /$ Jumlah penumpang per tahun $]$

$$
\begin{aligned}
& =(\text { Rp. } 117.070 .295,-+ \text { Rp. } 11.707 .029 / 21168) \\
& =\text { Rp. } 6.084,00
\end{aligned}
$$

Pembulatan $=$ Rp. $6 \cdot 000,00$

\section{ANALISA FINANSIAL}

1. Analisa Finansial (Kelayakan Usaha)

Untuk dapat melihat sejauh mana suatu investasi yang dilakukan dapat memberikan keuntungan atau tidak, maka perlu dilakukan analisa kelayakan investasi. Sebelum melakukan analisa kelayakan terlebih dahulu dibuat tabel cash flow. Dalam analisa kelayakan investasi ini kriteria-kriteria yang digunakan adalah Net Present Value, Benefit Cost Ratio, Internal Rate Return dan Payback Period.

Melihat keadaan tersebut, maka dalam menganalisis kelayakan usaha hanya dengan menggunakan kriteria $N P V$ yaitu selisih antara pendapatan dan biaya (cost) yang dikeluarkan untuk menghasilkan pendapatan dan Benefit Cost 
Rationya yaitu perbandingan antara pendapatan dan biaya (cost) yang dikeluarkan untuk menghasilkan pendapatan dan IRR yang digunakan karena para pengusaha memerlukan investasi dalam pengoperasian angkutan Umum dan yang mempunyai kewajiban untuk melakukan angsuran kaitannya dengan usaha pengoperasian angkutan umum tersebut.

a. Net Present Value (NPV)

Salah satu kriteria penilaian investasi dalam analisis finansial yang didapat dengan cara menghitung selisih antara nilai sekarang suatu investasi dengan nilai sekarang dari penerimaan-penerimaan kas bersih dimasa yang akan datang.

Jika nilai sekarang penerimaan-peneriamaan kas dimasa yang akan datang lebih besar dari nilai yang dilakukan, maka dapat dikatakan menguntungkan atau investasi tersebut dapat diterima (bermanfaat). Sedangkan jika lebih kecil maka investasi tersebut ditolak karena tidak menguntungkan.

1) Perhitungan Net Present Value (NPV)

$$
\begin{aligned}
& \text { NPV } \quad=\text { PV Benefit }- \text { PV Cost } \\
& \quad=\text { Rp. 3,461,428,195 - Rp 2,800,000,000 } \\
& =\text { Rp. } 661,428,195
\end{aligned}
$$

Dari hasil analisis finansial yang telah dilakukan untuk usaha Trayek K-32 menunjukkan bahwa trayek tersebut yang menunjukkan nilai net present value $(N P V)$ negatif. Dengan demikian pada trayek tersebut menguntungkan dan mengalami keuntungan sebesar Rp. $661,428,195$

\section{b. Benefit Cost Ratio (BCR)}

Benefit Cost Ratio merupakan perbandingan antara manfaat bersih dari tahun yang bersangkutan yang telah dinilai sekarang (pembilang bersifat positif) dengan biaya bersih dalam tahun dimana Benefit Cost (penyebut bersifat negatif) yang telah dinilai sekarang, yaitu biaya kotor lebih besar manfaat kotor.

Bt : Manfaat kotor/Benefit pada tahun 5

$\mathrm{Ct}$ : Biaya kotor/cost pada tahun 5

$\mathrm{n}$ : Ekonomis

i : Tingkat bunga bank yang berlaku $=9,90 \%$ 
$\mathrm{t} \quad:$ Tahun $=5$ tahun

1) Perhitungan Benefit Cost Ratio (BCR) pada tarif Bawah

Kriteria $B C$ Ratio ini jika $B C$ Ratio > 1. Maka usaha tersebut dapat diterima atau menguntungkan dan sebaliknya jika $B C$ Ratio $<1$, maka usaha tersebut tidak dapat diterima atau tidak menguntungkan. Nilai BCR yang didapat adalah 1,23 atau > 1 maka usaha dinyatakan layak atau menguntungkan.

c. Internal Rate Of Return (IRR)

Internal Rate Of Return (IRR) yaitu tingkat bunga (discount rate) yang dapat membuat besarnya NPV dar proyek sama dengan nol, atau yang dapat membuat $B C$ Ratio sama dengan satu. Dalam perhitungan IRR diasumsikan bahwa setiap benefit netto tahun secara otomatis ditanam kembali dalam tahun berikutnya dan memperoleh rate of return (tingkat bunga) yang sama dengan investasi - investasi sebelumnya. Jika IRR lebih besar dari social discount rate maka, investasi bisa diterima (menguntungkan).

d. Payback Period (PBP)

Payback Period suatu investasi menunjukkan berapa lama investasi dapat tertutup kembali dari aliran kas bersihnya. Jadi menunjukkan jangka waktu yang diperlukan untuk memperoleh kembali investasi yang telah dikeluarkan. Untuk mencari Payback Period dilakukan dengan cara mengurangkan investasi dengan aliran kas masuk setiap tahun. Untuk proyek yang tingkat resikonya tinggi metode ini sangat mudah diterapkan dengan menentukan payback period maksimum yang pendek.

1) Perhitungan Payback Period (PBP) pada tarif bawah

$$
\begin{aligned}
\mathrm{PBP} & =\frac{2,800,000,000}{661,428,195} \\
& =4,23
\end{aligned}
$$

Dari perhitungan PBP diatas maka dapat diketahui bahwa investasi akan kembali setelah 4 tahun 2 bulan investasi berjalan.

\begin{tabular}{|c|c|c|c|}
\hline INDIKATOR & NILAI & KETENTUAN & KETERANGAN \\
\hline NPV & $661,428,195$ & NPV POSITIF & LAYAK \\
\hline BCR & 1.236224355 & BCR $>1$ & LAYAK \\
\hline IRR & $17.80 \%$ & IRR $>10 \%$ & LAYAK \\
\hline
\end{tabular}




\begin{tabular}{|l|l|l|l|}
\hline PAYBACK & 4.23 & PP $<5$ & LAYAK \\
\hline
\end{tabular}

Sumber: Hasil Analisis Penulis

Berdasarkan tabel indicator diatas, kelayakan usaha trayek K-32 didapatkan layak untuk dilanjutkan, dengan asumsi jumlah armada 56 unit, sedangkan nilai balik investasi selama 4 tahun 2 bulan.

\section{KESIMPULAN DAN SARAN}

\section{A. Kesimpulan}

1. Jenis kendaraan dari trayek $\mathrm{K} 32$ ini adalah carry yang berwarna merah Kapasitasnya 12 penumpang Umur rata-rata dari kendaraan itu yaitu rat-rata dibuat pada tahun 1999, yaitu kurang lebih berumur 12 tahun . Keadaan fisik dari angkutan ini cukup baik, karena pada angkuatan ini diperoleh informasi bahwa sering dilakukan peremajaan seperti pengecetan, perbaikan mesin, dll sehingga kondisi fisiknya masih terlihat cukup baik.

2. Kecepatan yang meningkat karena pengemudi mengurangi waktu tunggu,hal ini juga di pengaruhi oleh jumlah armada yang banyak dan mengejar setoran.

3. Dari penghitungan menurut peraturan Dirjen Darat diatas, maka trayek SGCjatiwangin memerlukan armada sebanyak 56 unit mini bus dengan kapasitas 12 penumpang

4. Asumsi pengoperasian angkutan berdasarkan penghitungan jumlah armada yang sudah sesuai dengan peraturan Dirjen darat yaitu sebanyak 56 unit angkutan tiap hari. Dalam pengoperasian angkutan disesuaikan dengan jumlah penumpang. Penjadwalan ini dipertimbangkan dengan asumsi penjadwalan berdasarkan clock face

5. kelayakan usaha trayek K-32 didapatkan layak untuk dilanjutkan, dengan asumsi jumlah armada 56 unit, sedangkan nilai balik investasi selama 4 tahun 2 bulan.

\section{B. SARAN}

a. Untuk meningkatkan Pelayanan angkutan perlu adanya perhatian dari pemerintah terkait Regulasi dan penegakan ketertiban Angkutan Umum.

b. Perlu adanya suatu komitmen dan kebijakan dari Pemerintah Kabupaten Bekasiatau instansi yang terkait agar pelaksanaan angkutan umum dapat diimplementasikan.

c. Peningkatan peran serta pihak pengusaha dalam mendukung pelaksanaan pengoperasian angkutan umum agar dapat saling menguntungkan 